\title{
A TGMS-linked nuclear DNA marker as originated from the mitochondrial genome in rice (Oryza sativa L.)
}

\author{
PRASANTA K. SUBUDHI, SANT S. VIRMANI \& NING HUANG* \\ Plant Breeding, Genetics and Biochemistry Division, International Rice Research Institute, PO Box 933, 1099 Manila, \\ Philippines
}

\begin{abstract}
A nuclear RAPD marker, OPF18 2600 , was linked to a thermosensitive genetic male sterility (TGMS) gene (tms3) in a rice mutant line IR32364TGMS. Segregation analysis in two mapping populations and reciprocal cross analysis involving different genotypes indicated, however, that this marker was maternally inherited. The RAPD marker was then cloned as pF18 and partially sequenced from both ends of the insert. Sequence analysis showed that pF18 was homologous to mitochondrial genes, cob2 and nad1. Evidence was provided that the cob2 DNA segment near pF18 was genetically linked to tms3. Thus pF18 could be the result of integration of a piece of mitochondrial DNA segment into the nuclear genome. The transferred DNA segment included at the least cob2, a portion of nad1, and intergenic sequences. The presence of intron and intergenic sequences in the transferred DNA fragment indicated that DNA was the transfer intermediate. The relationship between the transferred DNA and $t m s 3$ is discussed.
\end{abstract}

Keywords: evolution, mitochondrial genes, RAPD, rice, sequence homology, TGMS.

\section{Introduction}

In Thermosensitive Genetic Male Sterility (TGMS), temperature is the key factor in determining the male fertility/sterility reaction of a genic sterile line. It has been reported that TGMS in rice is inherited in a normal Mendelian fashion and is under the control of a single recessive gene (Yang et al., 1990; Maruyama et al., 1991). Mapping analysis indicates that one of the TGMS genes is located on rice chromosome 8 (Wang et al., 1995). The molecular basis of TGMS is, however, poorly understood at present. On the contrary, cytoplasmic male sterility (CMS) has been widely studied and appears to be associated with DNA rearrangements in a specific mitochondrial region resulting in the synthesis of altered proteins thought to interfere with pollen development (for reviews see Hanson, 1991; Saumitou-Laprade et al., 1994; Vedel et al., 1994).

Recently, IRRI has developed a TGMS line, IR32364TGMS, which was induced by gamma irradiation (Virmani \& Voc, 1991). This gene was

\footnotetext{
*Correspondence and present address: Applied Phytologics, INC., 4110 N. Freeway, Sacramento, CA 95834, U.S.A. E-mail: huang@apinc.com
}

also found to be inherited in Mendelian fashion and was controlled by a single recessive gene, tms 3 (Borkakati \& Virmani, 1996). We initiated a study on this TGMS line with the final objective to elucidate the molecular basis of TGMS and to apply it to rice hybrid seed production. We identified four RAPD markers linked to tms 3 and located tms 3 on the short arm of chromosome 6 (Subudhi et al., 1997). One of the RAPD markers, OPF18 2600 was very peculiar. It was inherited as a nuclear marker in a Mendelian manner in the tms 3 mapping population, but was maternally inherited in other populations. This poses several intriguing questions. Is the marker nuclear inherited or maternally inherited? If nuclear inherited, why does it show cytoplasmic inheritance? If it is maternally inherited, is the marker locus in the chloroplast or mitochondrial genome? Can this be a piece of DNA from the cytoplasm integrated into the nuclear genome or vice versa? If there is transposition of a DNA fragment between genomes, what is the relationship between transposition and TGMS, if any?

Although we cannot answer all the questions in one study, we provide evidence based on segregation analysis, reciprocal cross analysis and a sequence 
homology search of the DNA sequence database, that $\mathrm{OPF} 18_{2600}$ is a mitochondrial-genome derived nuclear marker which cross-hybridizes to cytoplasmic DNA in other breeding lines. We hypothesize that this insertion represents a movement of DNA sequence from mitochondrion to nucleus.

\section{Materials and methods}

Plant materials and RAPD marker linked to tms3

An $\mathrm{F}_{2}$ population, from the cross IR32364TGMS (indica) $\times$ IR68 (indica), was used to map tms3 via bulked segregant analysis (Michelmore et al., 1991). The TGMS mutant line, IR32364TGMS, showed complete male-sterility at day/night temperatures of $32^{\circ} / 24^{\circ} \mathrm{C}$ but partial fertility at $27^{\circ} / 21^{\circ} \mathrm{C}$ in an IRRI phytotron. A RAPD marker, OPF $18_{2600}$, amplified by the random primer OPF18 (5'-TTCCCGGGTT-3') was found to be linked to tms3 (Subudhi et al., 1997).

\section{Cloning and sequencing of OPF $18_{2600}$}

The OPF $18_{2600}$ was reamplified twice to ensure uniformity of the fragment and purified by using a Geneclean kit (Bio 101). Then the purified fragment was cloned into pMosblue vector using a TA cloning system (Amersham Co.) by direct ligation. The cloned insert was spliced out by double digestion with EcoRI and $X b a \mathrm{I}$ to determine the correct size of the insert which should be $2.6 \mathrm{~kb}$. The identity of the cloned RAPD fragment was verified by hybridization of the cloned fragment to Southern blots of RAPD products amplified with OPF18 primer using DNA from the homozygous sterile and homozygous fertile individuals. The verified clone was named as pF18.

Double-strand sequencing of both ends of the clone was carried out by the dideoxy chain termination method (Sanger et al., 1977) using $\alpha^{32} \mathrm{P}$ dCTP and the Thermosequenase cycle sequencing kit (Amersham Co.). Based on the sequence information, primers (see Fig. 5 for primer sequences) were designed and another round of sequencing was carried out to obtain more sequence information.

\section{Mapping population and reciprocal crosses}

An effort was made to map pF18 onto rice chromosomes through the use of two mapping populations. At first, a doubled haploid population of 135 lines developed by anther culture from the cross between IR64 (indica) and Azucena (japonica) (Guiderdoni et al., 1992) was used, for which an RFLP framework map is available (Huang et al., 1994). The second mapping population was an $\mathrm{F}_{2}$ population derived from the cross of Tesanai $2 \times \mathrm{CB}$, obtained from the China National Rice Research Institute, China (Lin et al., 1996). Tesanai 2 is an indica variety from Guangdong, China and $\mathrm{CB}$, a variety inclining to indica type, is from California, USA. Another $F_{2}$ population derived from NPL12/Dular was also used to study the inheritance of $\mathrm{pF} 18$.

A reciprocal cross between the parents NPL12 and Dular was made to determine the pattern of inheritance. The IR32364TGMS and its original fertile breeding line IR32364 were also crossed with IR68 reciprocally. The $F_{1} \mathrm{~s}$ of these reciprocal crosses were used to examine the inheritance of pF18.

\section{DNA isolation and Southern analysis}

Total DNA from the parents, $F_{2}$ individuals of the TGMS cross-combination, constituent lines and parents of the mapping population and $F_{1} s$ of reciprocal crosses were extracted from fresh leaf tissues following the method of Dellaporta et al. (1983). Digested DNA was electrophoresed in a 0.9 per cent agarose gel, transferred to Hybond $\mathrm{N}+$ membrane and analysed by Southern analysis as described by Sambrook et al. (1989).

\section{PCR amplification of cob2 and nad1 gene segments}

After confirming the sequence homology between the sequences of $\mathrm{pF} 18, \operatorname{cob} 2$ and nad1 of rice and wheat, respectively, we wanted to know whether the whole cob2 and nad1 were integrated in the TGMS line. PCR primers were designed such that one primer annealed within $\mathrm{pF} 18$, and the other primer was based on sequences in GenBank. For cob2, we synthesized the forward primer, cob2F, 5'TCTCCTTTCCAAAGCTCCAC-3', based on the sequence in GenBank Acc. no. X53711 and the reverse primer, cob2R, 5'-TAAATCCTAGTGGAACCCGG-3', based on the DNA sequence of $\mathrm{pF} 18$. The expected size of the PCR product was $1470 \mathrm{bp}$. For nad1, the forward primer, nad1F, 5'-TCTTCCCCTAACCCAACCCG-3', was synthesized based on the pF18 sequence whereas nad1R, 5'-GCTGGGTAGGTTTGGCTATT-3', was based on the wheat nadl gene sequence (GenBank Acc. no. X57967). The expected PCR product was $2183 \mathrm{bp}$. The PCR amplifications were carried out following the method of Hittalmani et al. (1995). 
The PCR conditions were $94^{\circ} \mathrm{C}$ for $5 \mathrm{~min}$, followed by 30 cycles of $94^{\circ} \mathrm{C} 30 \mathrm{~s}, 55^{\circ} \mathrm{C} 30 \mathrm{~s}$, and $72^{\circ} \mathrm{C} 60 \mathrm{~s}$ with a final extension at $72^{\circ} \mathrm{C}$ for $5 \mathrm{~min}$.

\section{Results}

Linkage confirmation between tms3 and pF18 via Southern analysis

In the population developed from the cross between IR32364TGMS and IR68, four DNA bands were detected in the sterile parent, IR32364TGMS, whereas only three bands were detected in the fertile parent, IR68, when the DNA was digested with EcoRV and probed with pF18 (Fig. 1a). The $3.3 \mathrm{~kb}$ band in the sterile parent cosegregated with tms3 (Fig. 1b). All fertile homozygotes lacked the $3.3 \mathrm{~kb}$ band whereas all sterile plants had the $3.3 \mathrm{~kb}$ band. We therefore concluded that at least one band, detected by pF18, was linked to tms 3 and the band was in the nuclear genome as it segregated in the $\mathrm{F}_{2}$ population.

\section{Distorted segregation or maternal inheritance detected by $\mathrm{pF} 18$}

In order to map the tms3-linked marker, $\mathrm{pF} 18$, a doubled haploid mapping population consisting of 135 lines derived from the cross IR64 $\times$ Azucena was used (Guiderdoni et al., 1992). An RFLP map comprising 135 markers has been constructed (Huang et al., 1994) and used to map RAPD markers linked to genes of agronomical importance (Zhang et al., 1996). Polymorphism was detected in the parents by Southern blot analysis. However, the progeny survey indicated a complete bias in the segregation pattern in favour of the indica (IR64) allele (data not shown). We were puzzled by the strong segregation distortion of the pF18 marker, and assumed that the segregation distortion might be caused by the selection effect of anther culture. To avoid segregation bias resulting from anther culture, an $\mathrm{F}_{2}$ population derived from a cross between Tesanai 2 and CB (Lin et al., 1996) was used. Similarly, strongly skewed segregation in
Fig. 1 (a) An autoradiogram showing bulked segregant analysis using pF18 as the probe. Three enzymes, EcoRI, $E c o$ RV and $S c a$ I, were used for digestion. Only in the case of EcoRV is a $3.3 \mathrm{~kb}$ band evident in both the sterile parent and the sterile bulk. (b) Southern blot analysis of EcoRVdigested $\mathrm{F}_{2}$ progenies of the cross IR32364TGMS $\times$ IR68 using pF18 as the probe. The $3.3 \mathrm{~kb}$ band (indicated by an arrow) is present only in sterile and segregating fertile individuals indicating its dominant behaviour. $\mathrm{M}$, molecular weight marker (Lambda/ HindIII); SP, sterile parent IR32364TGMS; FP, fertile parent IR68; FB, fertile bulk; SB, sterile bulk.
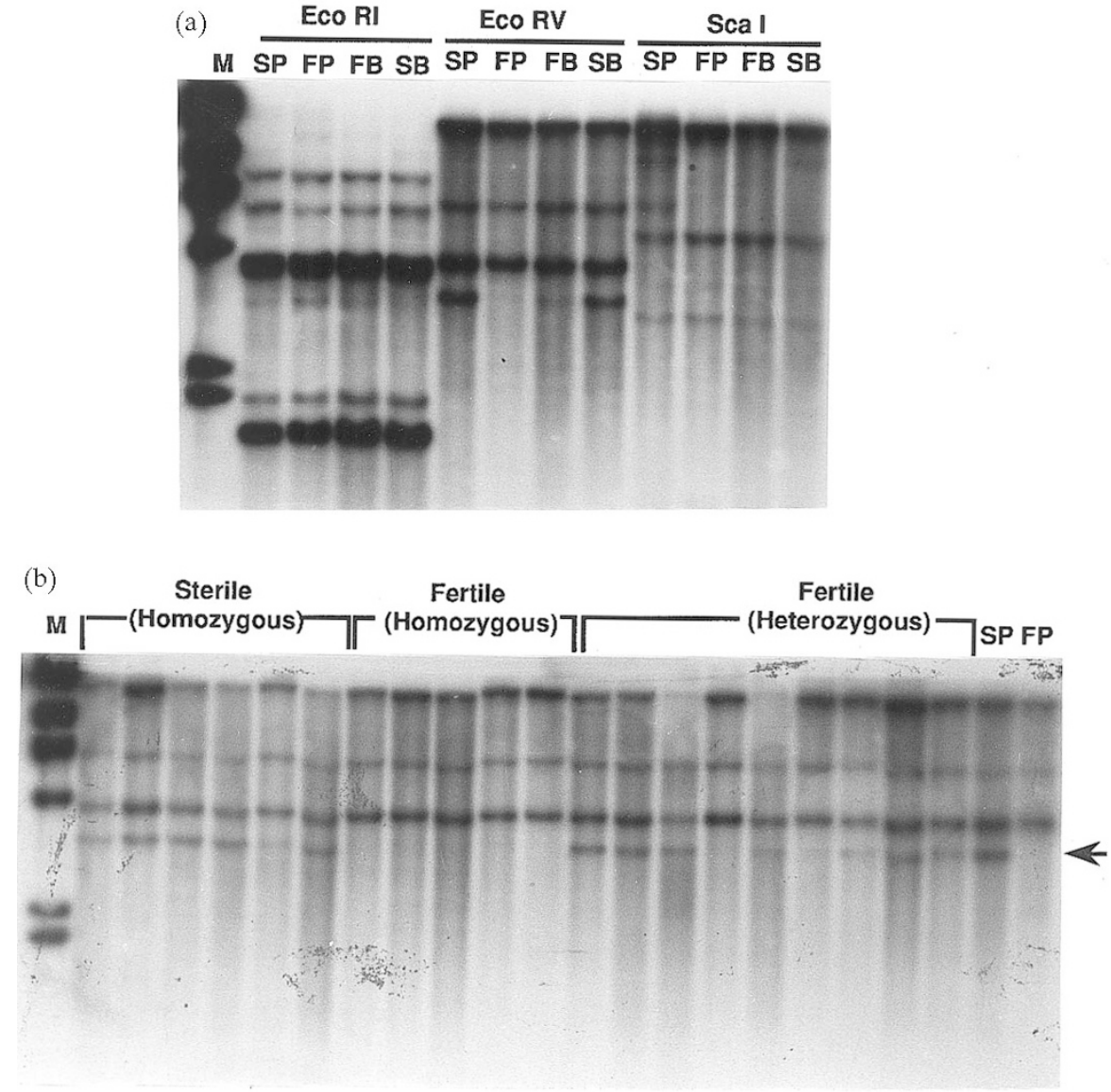
favour of the Tesanai 2 allele was observed (Fig. 2). We attempted a third $F_{2}$ population derived from a cross between Norin PL12 and Dular but the same strong bias of segregation was also found (data not shown).

As segregation distortion is common in indica $\times$ japonica crosses (Ikehashi \& Araki, 1988; Lin et al., 1992), we thought that pF18 might be tightly linked to a gene responsible for strong segregation distortion. Several such genes are already known in rice (Kinoshita, 1995). On the other hand, we also noticed that the bias in all three mapping populations was towards the female parents, implying maternal inheritance. Thus we hypothesized that pF18 might be originally derived from the cytoplasmic genome but transferred to the nuclear genome in IR32364TGMS. The marker sequence was therefore homologous to both nuclear (Fig. 1b) and organellar genomes. If this were true, Fig. 2 actually revealed cytoplasmic inheritance rather than strong segregation distortion.

\section{Maternal inheritance confirmed in reciprocal crosses}

The hypothesis of cytoplasmic (maternal) inheritance can be tested in reciprocal crosses. We analysed the reciprocal crosses involving the parents Norin PL12 and Dular (Fig. 3). All three maternal bands from Norin PL12 were present in $F_{1}$ individuals of Norin PL12 $\times$ Dular whereas only the Dular band was present in all the $F_{1}$ of Dular $\times$ Norin PL12. Maternal inheritance of $\mathrm{pF} 18$ was clearly evident.

Reciprocal crosses of IR32364TGMS $\times$ IR68 were also analysed. Fig. 4 shows the inheritance of the $3.3 \mathrm{~kb}$ Eco RV polymorphic fragment. The fragment was present in both crosses. Identical results were
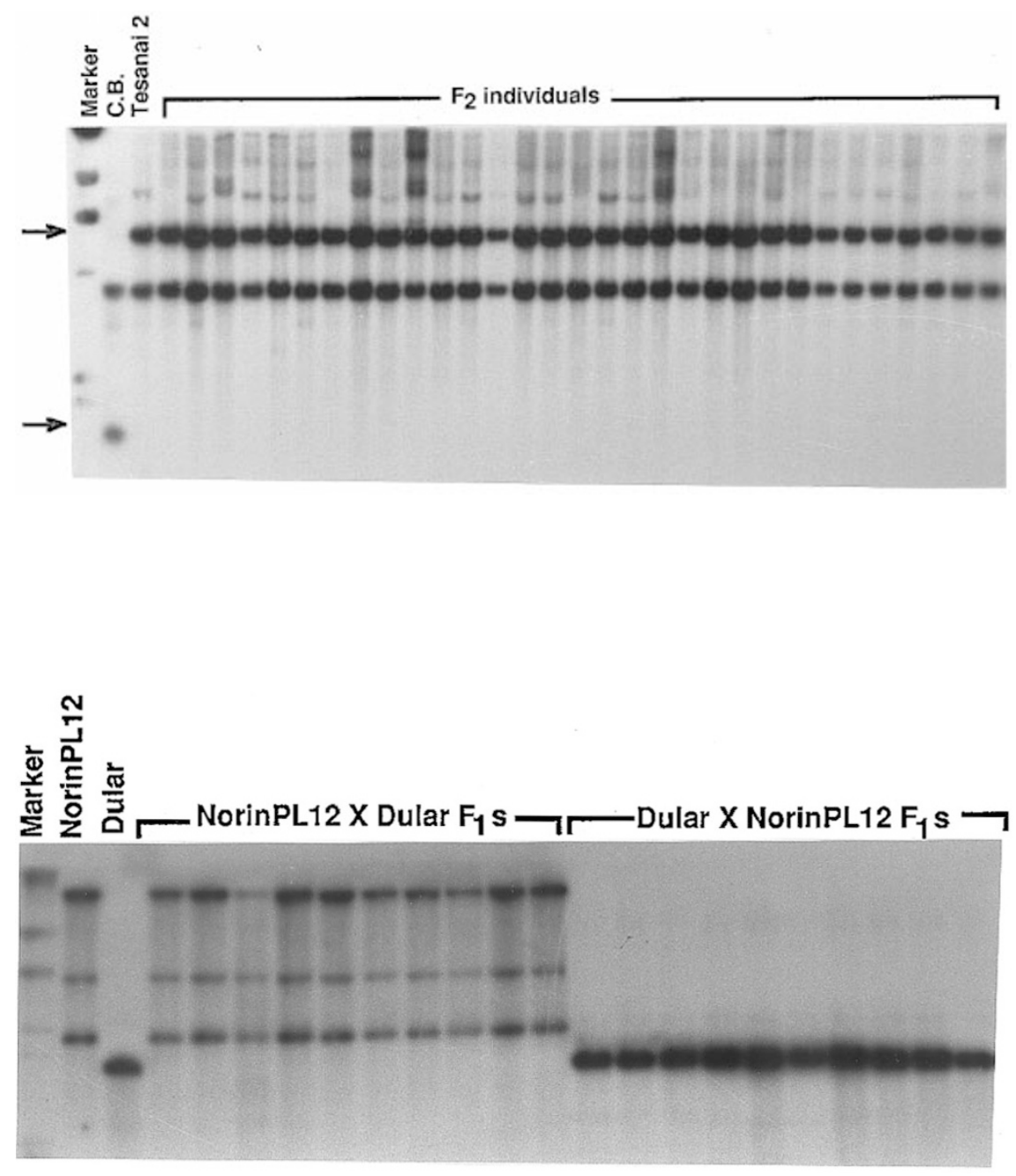

Fig. 2 Southern blot analysis of EcoRI-digested Tesanai $2 \times \mathrm{CB} \mathrm{F}_{2}$ individuals using $\mathrm{pF} 18$. Tesanai 2 and $\mathrm{CB}$ alleles are indicated by arrows. Only Tesanai 2 alleles are inherited in all individuals.

Fig. 3 Southern analysis of EcoRVdigested total genomic DNA derived from $\mathrm{F}_{1} \mathrm{~s}$ of reciprocal crosses of Norin PL12 $\times$ TDular using pF18 as probe. 
Fig. 4 Southern analysis of Eco RVdigested total genomic DNA in reciprocal crosses of IR32364TGMS $\times$ IR68 using $\mathrm{pF} 18$ as probe.
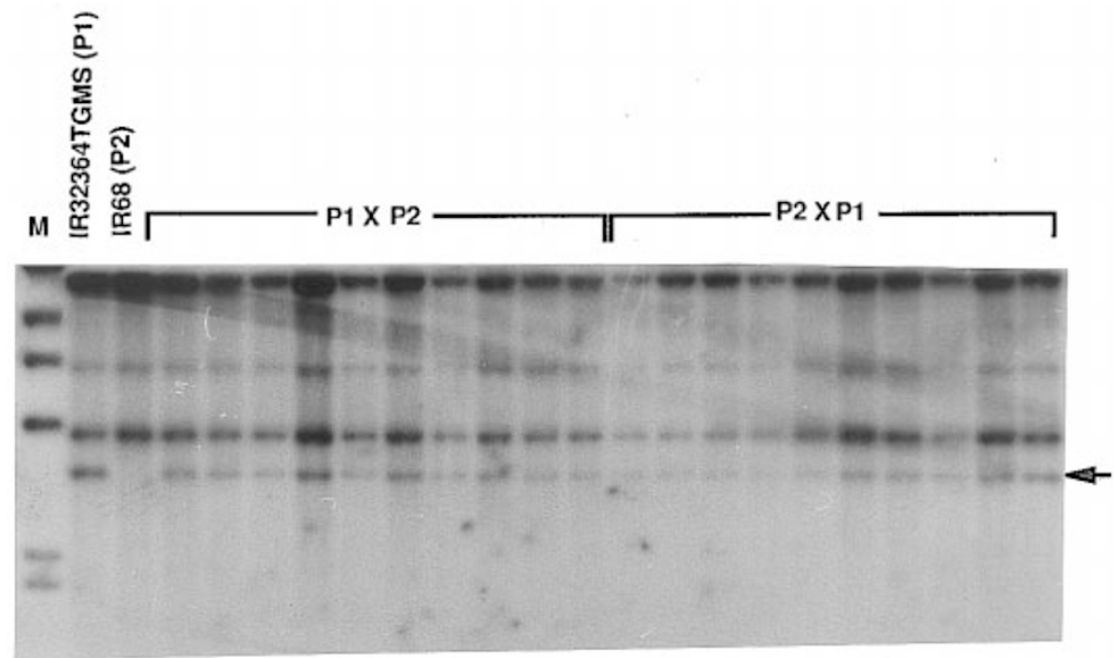

also obtained in reciprocal crosses of IR32364 $\times$ IR68 (data not shown). This clearly indicates nuclear inheritance of pF18 in the TGMS mapping population as well as in IR32364, the original fertile line used for mutagenesis. It can therefore be concluded that the pF18 marker loci were present in both nucleus and cytoplasm.

\section{pF18 contains a mitochondrial DNA sequence}

As pF18 was homologous to a DNA sequence in the cytoplasm, it was interesting to know if it was in the chloroplast or mitochondrial genomes. The pF18 was partially sequenced from both ends. A DNA sequence of $677 \mathrm{bp}$ was obtained from the EcoRI end of the clone and named PF18F (Fig. 5a). Similarly, a DNA sequence of 626 bp was obtained from the $X b a \mathrm{I}$ end of the insert and named PF18R (Fig. 5b). A homology search of GenBank revealed that pF18 was highly homologous to the mitochondrial genes of many species. The rice pseudo-apocytochrome (cob2) gene (Acc. no. X53711) was homologous to PF18F, whereas PF18R was homologous to the nad1b, 1c gene of wheat (Acc. no.
Fig. 5 (a) Sequence alignment of PF18F with rice pseudo-apocytochrome b (cob2) gene (Acc. no. X53711). Duplicated sequences are underlined. The $192 \mathrm{bp}$ conserved sequence of $c o b 2$ is italicized. Sequences in bold letters match B4 plasmid-like sequence (Fukuchi et al., 1991). (b) Sequence alignment of PF18R with the wheat nad1 gene segment (Acc. no. X57967). The coding region is shown by lower case letters in the cob2 and nad1 sequences. Annealing position of primers for sequencing and PCR are indicated. (a)

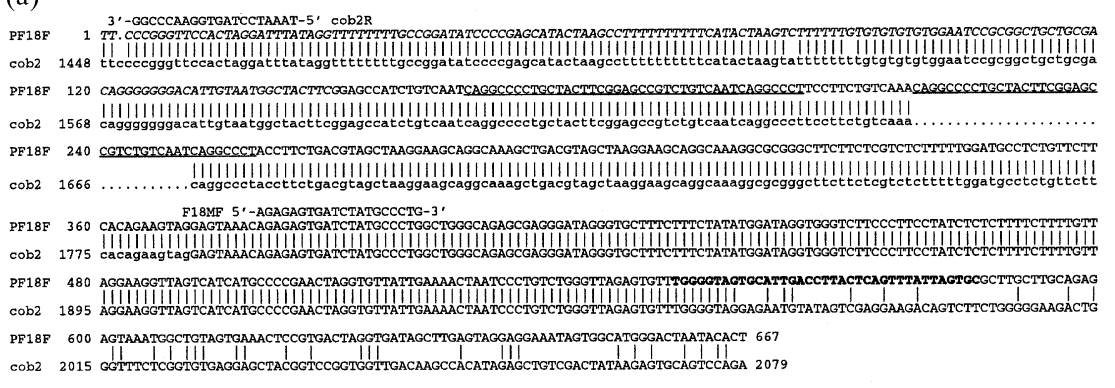

(b)

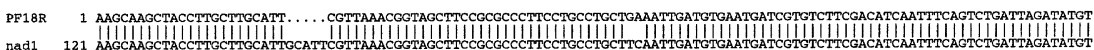

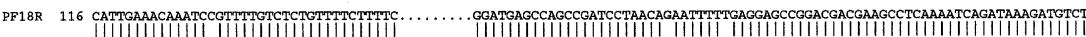

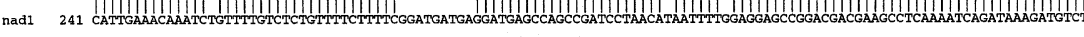

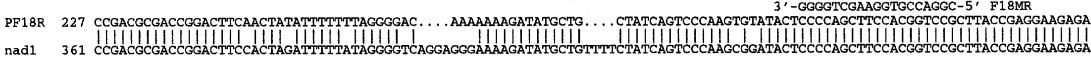

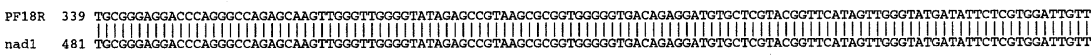

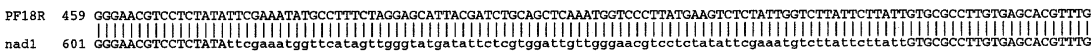
nad1F $5^{\prime}$--тCTтCCCCDAACCCAACCCG-3.

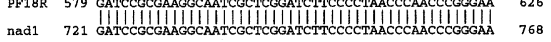


X57967), and nad1-like sequences of different species such as maize (Acc. no. M18339), petunia (Acc. no. X60401), and watermelon (Acc. no. X04130).

The sequence alignment of the cob2 and nad1 segments with $\mathrm{pF} 18$ is shown in Fig. 5. From Fig. 5(a) it is evident that PF18F was highly homologous to the rice cob2 gene but the sequences diverged drastically after the $550 \mathrm{bp}$ position. Within the homologous region, a $33 \mathrm{bp}$ duplication was noticed in PF18F. A few features of PF18F are worthy of comment. First, the sequence of PF18F from positions 1-370 corresponded to a coding region and the stop codon in cob2 indicating that PF18F contained both coding and noncoding regions. Secondly, PF18F contained the $192 \mathrm{bp}$ conserved sequence of the cob2 genes (Narayanan $e t$ al., 1995). Thirdly, a $37 \mathrm{bp}$ sequence spanning homologous and nonhomologous regions of PF18F completely matched the B4 plasmid-like sequences which had been shown to transfer from mitochondrion to nucleus (Fukuchi et al., 1991).

The sequence of PF18R was highly homologous to the $n a d 1 \mathrm{~b}$ and $1 \mathrm{c}$ gene segments of the wheat mitochondrial genome (Fig. 5b). The sequences from the 475-557 bp positions of PF18R corresponded to the first exon of nad1. The rest of the sequences in the PF18R segment were introns (Fig. 5b). Because cob2 and nad1 were commonly present in the mitochondrion, it was concluded that pF18 was transferred from mitochondrial to nuclear genomes.

\section{Linkage of cob2 with tms3}

If $\mathrm{pF} 18$ were transferred from mitochondrion to nucleus, and if the transferred fragment included entire cob2 and nad1 genes, then cob2 and nad1 should link to tms 3 as well. To test this hypothesis, PCR primers were synthesized based on sequences of GenBank for both genes and sequence of pF18 (see Materials and methods for detail). PCR products of the expected size $(1470 \mathrm{bp})$ were obtained for cob2, whereas there was limited amplification of low molecular weight fragments for nad1 (data not shown), therefore PCR analysis in segregating populations was conducted for cob2 only.

The PCR analysis was first analysed with the doubled haploid lines of the IR64/Azucena population (Fig. 6a). A PCR band from IR64 is slightly larger than that from Azucena, showing codominant polymorphism. The progeny survey showed that all $\mathrm{DH}$ lines carried the band from the female parent, indicating that the cob2 was inherited in maternal fashion in the IR64/Azucena population and the
PCR products must be amplified from mitochondrial DNA.

In the IR32364TGMS $\times$ IR68 population, two bands were amplified from IR32364TGMS DNA, with the top band stronger than the lower one, whereas only one band was obtained with DNA from IR68 (Fig. 6b). Comparing the PCR bands from both parents, we found that one band was in common. As we know there is no gene insertion in IR68, the common bands in IR68 and IR32364TGMS must be derived from the mitochondrion. The other band in IR32364TGMS produces the dominant-type polymorphism as pF18. A survey of this band among sterile (with tms3) and fertile (without tms3) plants showed that all sterile plants
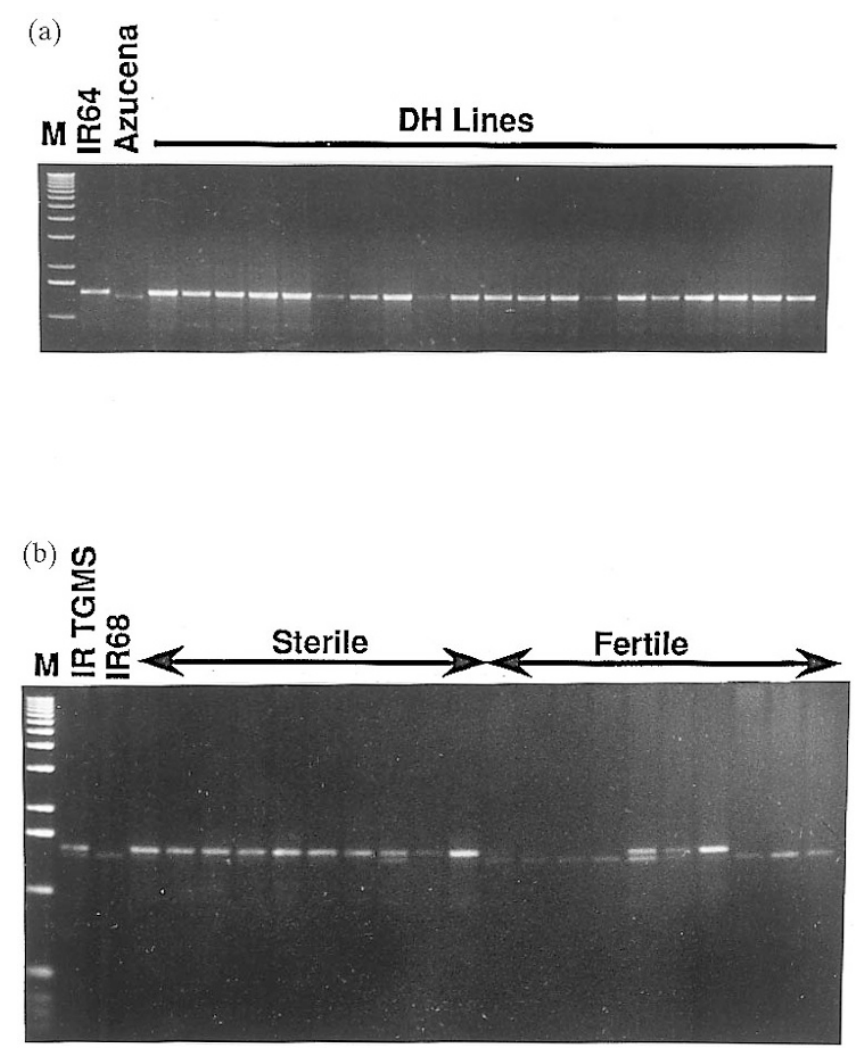

Fig. 6 PCR amplification of the cob2 gene from total genomic DNA of rice. (a) PCR product from IR64 and Azucena showed two different alleles of $c o b 2$ with a small difference in molecular weight. Maternal inheritance is clearly evident because of the amplification of only the IR64 (female parent) allele. (b) Two cob2 alleles were present in IR32364TGMS whereas only one allele was present in IR68. PCR amplification of the cob2 gene was conducted for the homozygous sterile and homozygous fertile $\mathrm{F}_{2}$ individuals. $\mathrm{M}$, molecular weight marker, $\mathrm{kb}$ ladder. 
carried the dominant band, whereas only three of the 10 fertile plants carried the dominant marker. This demonstrated that cob2, like pF18, is also linked to tms3 (Fig. 6b).

\section{Discussion}

Three lines of evidence have been provided that pF18 was derived from the mitochondrion: (i) pF18 was maternally inherited in three different populations (a doubled haploid and two $F_{2}$ populations) involving six different varieties; (ii) the maternal inheritance of pF18 was further confirmed by the observation of uniparental inheritance in reciprocal crosses; and (iii) the DNA sequence of pF18 was highly homologous to mitochondrial genes (cob2 and nad1) of several plant species. It was therefore concluded that $\mathrm{pF} 18$ was transferred from the mitochondrion into the nuclear genome. A mapping study indicated that the insertion point was on the short arm of chromosome 6 (Subudhi et al., 1997).

There are several interesting features about this insertion. The first is that the transfer of $\mathrm{pF} 18$ was a DNA intermediate. Before our study, there had been ample evidence for transfer of genetic material from the mitochondria to nuclei documented in various flowering plants (see Fukuchi et al., 1991; Nugent \& Palmer, 1991; Grohmann et al., 1992 for examples), showing flexible genetic information transfer among cellular compartments. Because the nuclear genomic sequences more closely resembled the edited sequences than the actual mitochondrial genes (Fukuchi et al., 1991; Nugent \& Palmer, 1991; Covello \& Gray, 1992; Grohmann et al., 1992), it was generally believed that an RNA intermediate was used during the transfer process. However, one report in Arabidopsis indicated involvement of a DNA intermediate (Sun \& Callis, 1993). As pF18 contained exon, intron and intergenic sequences, we believe that $\mathrm{pF} 18$ was transferred via a DNA intermediate.

The second main feature of $\mathrm{pF} 18$ is its large size. Although the actual size of the insertion or the position of its borders are still unclear, the insertion includes both the $2.6 \mathrm{~kb} \mathrm{pF} 18$ and $1.5 \mathrm{~kb}$ of cob2, so it is larger than $4.1 \mathrm{~kb}$. To the best of our knowledge, this is the largest recorded DNA segment transferred from the mitochondrion into the nucleus. The insertion includes at least cob2, part of nad1 and intergenic sequences. It remains to be clarified if the insertion is derived from a single continuous mitochondrial DNA segment or ligated DNA segments from several positions in the mitochondrial genome prior to DNA transfer.
The third interesting feature of the insertion is its genetic linkage to tms3. Furthermore, cob2, part of the insertion, has been shown to be associated with the wild abortive (WA) type cytoplasmic male sterility (cms) (Narayanan et al., 1995). Rearrangement of mitochondrial DNA has been demonstrated to be responsible for the T-type $\mathrm{cms}$ in maize. The mitochondrial gene, T-urf13, which is present in $\mathrm{T}$ cytoplasm but absent in normal cytoplasm, is responsible for the male sterility (Levings, 1993). Thus one might ask about the relationship between the pF18 insertion and cms or TGMS. Further study on the structure and function of the insertion might shed more light on this.

\section{Acknow ledgements}

The postdoctoral fellowship granted to P. K. Subudhi by the Rockefeller Foundation is gratefully acknowledged. The authors are thankful to Arnold Parco, and Mila Lopez for their kind help during the course of the investigation and Prof. K. Zheng of CNRRI, China for sharing the filters of the mapping population for Southern analysis.

\section{References}

BORKAKATI, R. P. AND VIRMANI, s. S. 1996. Genetics of thermosensitive genic male sterility in rice. Euphytica, 88, 1-7.

COVELlO, P. S. AND GRAY, M. W. 1992. Silent mitochondrial and active nuclear genes for subunit 2 of cytochrome c oxidase $(\cos 2)$ in soyabean: evidence for RNA mediated gene transfer. EMBO J, 11, 3815-3820.

DEllaportA, S. L., WOOD, J. AND Hicks, J. B. 1983. A plant DNA minipreparation: version II. Plant Mol. Biol. Rep., 1, 19-21.

FUKUCHI, M., SHIKANAI, T., KOSSYKH, V. G. AND YAMADA, Y. 1991. Analysis of nuclear sequences homologous to the B4 plasmid-like DNA of rice mitochondria; evidence for sequence transfer from mitochondria to nuclei. Curr. Genet., 20, 487-494.

GROHMANN, L., BRENNICKE, A. AND SCHUSTER, W. 1992. The mitochondrial gene encoding ribosomal protein $\mathrm{S} 12$ has been translocated to the nuclear genome in Oenothera. Nucl. Acids Res., 20, 5641-5646.

GUIDERDONi, E., GALINATO, E., LUISTRO, J. AND VERGARA, G. 1992. Anther culture of tropical japonica $\times$ indica hybrids of rice (Oryza sativa L.). Euphytica, 62, 219-224. HANSON, M. R. 1991. Plant mitochondrial mutations and male sterility. Ann. Rev. Genet., 25, 461-486.

HITTALMANI, S., FOOLAD, M. R., MEW, T., RODRIGUEZ, R. L. AND HUANG, N. 1995. Development of a PCR-based marker to identify rice blast resistance gene, $P i-2(t)$ in a segregating population. Theor. Appl. Genet., 91, 9-14.

HUANG, N., McCOUCH, s. R., MEW, T., PARCO, A. AND GUIDERDONI, E. 1994. Development of an RFLP map from 
a doubled haploid population in rice. Rice Genet. Newsl., 11, 134-137.

IKEHASHI, H. AND ARAKI, H. 1988. Multiple alleles controlling $\mathrm{F}_{1}$ sterility in remote crosses of rice (Oryza sativa L.). Jap. J. Breed., 38, 283-291.

KinoshitA, т. 1995. Report of the Committee on Gene Symbolization, Nomenclature and Linkage Groups. Rice Genet. Newsl., 12, 9-153.

LEVINGS, C. S., III. 1993. Thoughts on cytoplasmic male sterility in cms-T maize. Pl. Cell, 5, 1285-1290.

LIN, H. X., QIAN, H. R., ZHUANG, J. Y., LU, J., MIN, S. K., XIONG, Z. M. ET AL. 1996. RFLP mapping of QTLs for yield and other related characters in rice (Oryza sativa). Theor. Appl. Genet., 92, 920-927.

LIN, S. Y., IKEHASHI, H., YANAGIHARA, S. AND KAWASHIMA, K. 1992. Segregation distortion via male gametes in hybrids between indica and japonica or wide compatibility varieties of rice (Oryza sativa L.). Theor. Appl. Genet., 84, 812-818.

MARUYAMA, K., ARAKI, H. AND KATO, H. 1991. Thermosensitive genic male sterility induced by irradiation. In: Rice Genetics, II, pp. 227-235. IRRI, Manila, Philippines.

MICHELMORE, R. W., PARAN, I. AND KESSELI, R. V. 1991. Identification of markers linked to disease resistance genes by bulked segregant analysis: a rapid method to detect markers in specific genomic regions by using segregating populations. Proc. Natl. Acad. Sci. U.S.A., 88, 9828-9832.

NARAYANAN, K. K., SENTHILKUMAR, P., SRIDHAR, V. V., THOMAS, G. AND THOMAS, J. 1995. Organization of the mitochondrial cob2 pseudogene in different lines of rice. Theor. Appl. Genet., 90, 1087-1093.

NUGENT, J. M. AND PALMER, J. D. 1991. RNA mediated transfer of the gene coxII from the mitochondrion to the nucleus during flowering plant evolution. Cell, 66, 473-481.
SAMBROOK, J., FRITSCH, E. F. AND MANIATIS, T. 1989. Molecular Cloning: A Laboratory Manual. Cold Spring Harbor Laboratory Press, New York.

SANGER, F., NICKLEN, S. AND COULSON, A. R. 1977. DNA sequencing with chain terminating inhibitors. Proc. Natl. Acad. Sci. U.S.A., 74, 5463-5467.

SAUmitou-laprade, P., CUGUen, J. AND Vernet, P. 1994. Cytoplasmic male sterility in plants: molecular evidence and the nucleocytoplasmic conflict. Trends Ecol. Evol., 9, 431-435.

SUBUDHI, P. K., BORKAKATI, R. P., VIRMANI, S. S. AND HUANG, N. 1997. Molecular mapping of a thermosensitive genetic male sterility gene in rice using bulked segregant analysis. Genome, 40, 188-194.

SUN, C. W. AND CALLIS, J. 1993. Recent stable insertion of mitochondrial DNA into an Arabidopsis polyubiquitin gene by nonhomologous recombination. Pl. Cell, 5, 97-107.

VEDEl, F., PLA, M., VITART, V., GUTIERRES, S., CHETRIT, P. AND DE PAEPE, R. 1994. Molecular basis of nuclear and cytoplasmic male sterility in higher plants. Pl. Physiol. Biochem., 32, 601-618.

VIRMANI, s. S. AND VOC, P. C. 1991. Induction of photo and thermosensitive genic male sterility in indica rice. Agron. Abstr., 119.

WANG, B., XU, W., WANG, J., WU, W., ZHENG, H., YANG, Z. ET $A L$. 1995. Tagging and mapping the thermosensitive genic male sterile gene in rice (Oryza sativa L.) with molecular markers. Theor. Appl. Genet., 91, 1111-1114.

YANG, Y. C., WANG, N. Y., LIANG, K. J. AND CHEN, Q. H. 1990. Thermosensitive genic male sterile rice R59TS. Sci. Agric. Sin., 23, 90 (in Chinese).

ZHANG, G., ANGEles, E. R., ABENES, M. L. P., KHUSH, G. S. AND HUANG, N. 1996. RAPD and RFLP mapping of the bacterial blight resistance gene $x a-13$ in rice. Theor. Appl. Genet., 93, 65-70. 